\title{
Two Corpus-Based Approaches to Rap Flow
}

\author{
JACOB GRAN \\ Louisiana State University
}

\begin{abstract}
This commentary compares and contrasts the two articles within this issue that describe a corpus-based approach to rap music (Condit-Schultz, 2016; Ohriner 2016). Beyond their technical differences, these studies mutually converge on the concept of "flow" as a window into the technical problems of analyzing rap music, and the results of the two studies complement one another. The comparison of these essays allows a unique insight into the methodological alternatives available within corpusbased research. I also attempt to briefly contextualize these essays within the history of the field, and to outline what I believe their significance to be as contributions to the musicology of rap music.
\end{abstract}

Submitted 2016 July 15; accepted 2016 October 12.

KEYWORDS: rap, rap music, corpus, corpus studies, flow

THIS edition of Empirical Musicology Review features two corpus studies of rap music. Just as this issue can be seen as a point of arrival for corpus study research, these articles can be seen as culminations of previous research in the field of rap music. As Nathaniel Condit-Schultz (2016) fairly describes in his literature review, early musicological inquiry into rap music focused primarily on rap's sociological and ethnomusicological significance. Theoretical research was late to the party, and largely focused its attention on rap's aspect as a form of poetry. Perhaps the analyses produced with conventional analytical tools, directed as they are at tonality, melody, and form, are unsatisfying as ends in themselves when employed on a repertoire that is premised on simple, repetitive harmonic hooks, half-spoken melodies, and "sampling" from other composers and songwriters. Instead, conventional analysis has been brought into service to fortify arguments that are basically historical or ethnographic, as in formative books by Adam Krims and Joseph Schloss (Krims, 2000; Schloss, 2004).

A theory of rap music requires, like all popular music, its space of operation to be hammered out and negotiated by the first generation of scholars. This initial activity is a form of music criticism, and it involves both the necessary critiques of the field of research to make independent, unapologetic study possible as well as a transferring of the responsibility for the critical defense of the repertoire from journalism to academia. Nathaniel Condit-Schultz's "MCFlow: A Digital Corpus of Rap Transcriptions" and Mitchell Ohriner's "Metric Ambiguity and Flow in Rap Music: A Corpus-Assisted Study of Outkast's 'Mainstream' (1996)" do not waste any time defending rap music as an object of study, except insofar as to defend its value as music. Both authors, following the lead of Kyle Adams, theorize rap musicality (as opposed to its poetry) in terms of flow (Adams, 2009). Flow is the rhythmical aspect of rap delivery that distinguishes it from other forms of poetry, and that affords it its musicality. The corpus study approach is particularly well-suited to addressing the multifaceted detail of this aspect of the rap repertoire.

Adams breaks his description of flow into three main components: 1) the placement of accented syllables, 2) the placement of rhymed syllables, and 3) the correspondence between syntactical and metrical units (Adams, 2009). The two corpora in this issue encode these features in different ways. "Accent" is a problematic concept, especially when applied to rap music. The patterns of natural syllable stress in the English language are conditioned in rap by metrical, agogic, and intonational stresses from the vocal delivery and musical background. Ohriner's approach to accent is pragmatic; he designed an algorithm that he believes reproduces an intuitive identification of rap accent. Condit-Schulz encodes the lower-level components of accent as separate data spines: syllable stress, pitch accent, and melody. Accent as a phenomenon is captured implicitly by this lower-level data. Ohriner deals with rhyme by encoding a numbered series of "rhyme classes" in each transcription. The first occurrence of a rhyme in a song would be designated as part of the first rhyme class and so on. Like his approach to accent, Ohriner does not permit a formulaic definition to preclude intuitive judgements about what constitutes membership in a rhyme class and what does not. Condit-Schulz approaches rhyme through what he calls "rhyme motives," a sequence of parallel phonemes that are not necessarily adjacent. The rhythmic placement of accents and rhymes is indicated in Ohriner's corpus through a pair of integers he calls a "beat index." Rhythm in Condit-Schulz's corpus is a separate spine, and so again the placement of accent and rhyme are not encoded directly but emerge out of 
lower-level encoding. This bottom-up approach is common to both corpora with respect to the last feature of flow; the interaction of metrical and syntactic units. Ohriner and Condit-Schulz both encode syntactical and prosodic features separately, permitting their interactions (like enjambment) to be teased out by the analyst.

The two authors used quite different selection criteria for song inclusion in their corpora. Even still, the corpora likely share a significant amount of sampling overlap. These differences in selection criteria also reveal the differences in analytical priorities between the two articles. MCFlow takes its samples primarily from the Billboard top 100 charts. For Condit-Schultz, this allows the selection to be based on consumer preference, and the sampled songs can be taken as exemplars of the idiom. As recognized by the author, this has two disadvantages. First, the resulting sample will not include the "underground" rappers who may have been formative influences on the style but did not themselves produce hits. Second, the sampling will be disproportionately comprised of singles, as opposed to deeper cuts on an album. Condit-Schultz also included an additional batch of samples from 1980's rap that would have been underrepresented if his corpus was based on the Billboard charts alone but which are necessary for adequate comparisons between the old and new schools of rap. Orhiner designed his samples around a number of different criteria in an effort to remove sampling bias. This included Complex Magazine's lists of the "Best Selling Albums of All Time" and the "Fifty Most Slept-On Rappers." He also includes smaller corpora assigned to emcees T-Mo Goodie and André 3000 for the purposes of comparison.

Both corpora arrived at similar results. Both found a preponderance of end rhymes occurring on or near successive fourth beats of the measure (clinching a minor assertion about style made by Adams in his 2009 article). Whereas Condit-Schulz's application of the corpus was aimed at diagnosing historical trends, Ohriner's article ends with a close reading of one of his oddest outliers; emcee T-Mo Goodie's first verse from "Mainstream" (1996) by Outkast. In this verse, the drums articulate common meter while the rapping is more neatly understood with triple groupings. This is an example of the kind of rhythmic play that these corpora should draw to our attention, highlighting the peculiarity of a given passage with respect to a wider corpus. By way of comparison, a flow analysis by Martin Connor of quintuplet patterns in Outkast's “Aquemini” (1998) draws similar conclusions about André 3000's style of flow (Connor, 2013). Ohriner's corpus proves that it can empirically identify critically salient passages of flow and highlight the specific ways in which outlying passages deviate from stylistic norms.

Although I began the commentary by commending the author's approach to rap as music, I feel that both authors might have benefitted from including a brief discussion of the performativity of rap and the unique problems faced by a corpus approach to a basically performative musical tradition. By encoding recordings, we take as our analytical object something with fixed internal relationships, and it is not necessarily the case that the complete meaning of the term "flow" would be captured by such an approach. In addition, a discussion of performativity would reinforce the overarching distinction between rap as poetry and rap as music (i.e., rap as text vs. rap as performance). It is this demonstration of the musicality of rap that I take to be these essays' most important contributions to the study of their repertoire.

\section{REFERENCES}

Adams, K. (2009). On the Metrical Techniques of Flow in Rap Music. Music Theory Online, 15(5).

Condit-Schultz, N. (2016). MCFlow: A Digital Corpus of Rap Transcriptions. Empirical Musicology Review 11(2), 124-147. https://doi.org/10.18061/emr.v11i2.4961

Connor, M. (2013). The Rapper's Flow Encyclopedia [blog post]. Retrieved from http://genius.com/posts/1669The-rapper-s-flow-encyclopedia

Krims, A. (2000). Rap Music and the Poetics of Identity. Cambridge: Cambridge University Press.

Ohriner, M. (2016). Metric Ambiguity and Flow in Rap Music: A Corpus-Assisted Study of Outkast's

“Mainstream” (1996). Empirical Musicology Review 11(2), 148-152. https://doi.org/10.18061/emr.v11i2.4896

Schloss, J. (2004). Making Beats: The Art of Sampling-Based Hip Hop. Middleton, CT: Wesleyan University Press. 